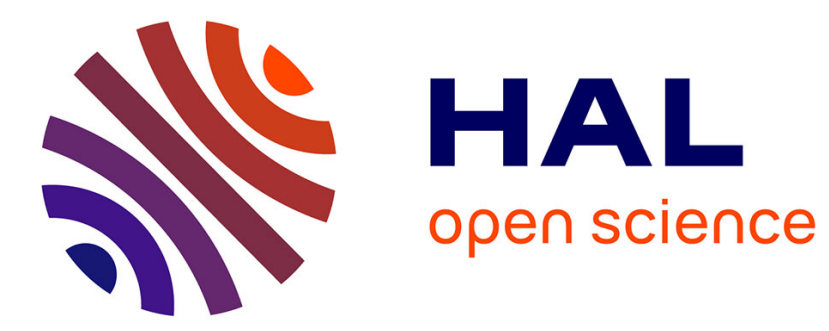

\title{
Spatiotemporal characteristics of Portevin-Le Chatelier effect in Ti-Mo alloys under thermo-mechanical loading
}

\author{
S. Luo, P. Castany, S. Thuillier, M. Huot
}

\section{To cite this version:}

S. Luo, P. Castany, S. Thuillier, M. Huot. Spatiotemporal characteristics of Portevin-Le Chatelier effect in Ti-Mo alloys under thermo-mechanical loading. Materials Science and Engineering: A, 2018, 733, pp.137-143. 10.1016/j.msea.2018.07.022 . hal-01874722

HAL Id: hal-01874722

https://hal-univ-rennes1.archives-ouvertes.fr/hal-01874722

Submitted on 18 Sep 2018

HAL is a multi-disciplinary open access archive for the deposit and dissemination of scientific research documents, whether they are published or not. The documents may come from teaching and research institutions in France or abroad, or from public or private research centers.
L'archive ouverte pluridisciplinaire HAL, est destinée au dépôt et à la diffusion de documents scientifiques de niveau recherche, publiés ou non, émanant des établissements d'enseignement et de recherche français ou étrangers, des laboratoires publics ou privés. 


\title{
ACCEPTED MANUSCRIPT
}

\section{Spatiotemporal Characteristics of Portevin-Le Chatelier Effect in Ti-Mo alloys under Thermo-Mechanical Loading}

\author{
Shiyuan Luo ${ }^{\mathrm{a}, *}$, Philippe Castany ${ }^{\mathrm{b}}$, Sandrine Thuillier ${ }^{\mathrm{a}}$, Makara Huot ${ }^{\mathrm{a}, \mathrm{b}}$ \\ ${ }^{a}$ Univ. Bretagne Sud, UMR CNRS 6027, IRDL, F-56100 Lorient, France \\ ${ }^{\mathrm{b}}$ Univ Rennes, INSA Rennes, CNRS, ISCR - UMR 6226, F-35000 Rennes, France
}

\begin{abstract}
The Portevin-Le Chaterlier (PLC) effect in Ti-12Mo and Ti-15Mo alloys has been investigated by using uniaxial tensile tests in a temperature range of $25-350{ }^{\circ} \mathrm{C}$ with an applied strain rate of the order of $10^{-3} \mathrm{~s}^{-1}$, coupled with a digital image correlation (DIC) method. The experimental results show an increase of the yield stress from $25^{\circ} \mathrm{C}$ to $250^{\circ} \mathrm{C}$ followed by a decrease. Moreover, PLC effect occurs above $250^{\circ} \mathrm{C}$ and stress drop magnitude increases while the number of stress drops per unit time decreases with increasing the strain and temperature as well as decreasing Mo contents. These macroscopic features are related to the reduced intensity of interactions between $\omega$ phase particles and mobile dislocations as decreasing temperature and increasing Mo contents. Furthermore, a relatively higher temperature and lower Mo content tend to weaken the spatial cohesion of propagation bands and strengthen strain localization, leading to a change of PLC bands from type A to type B and the increase of strain rate within the PLC bands, which are related to the increased precipitation of $\omega$ phases. Additionally, the elongation at fracture is significantly influenced by PLC effect in Ti-Mo alloys.
\end{abstract}

Keywords: Titanium alloys; Portevin-Le Chatelier effect; $\beta$ phase; Thermo-mechanical behavior; Digital image correlation

*Corresponding author. Tel.: +33 784467480. E-mail address: shiyuan.luo@univ-ubs.fr (S.Y. Luo) 


\section{Introduction}

Titanium alloys are widely used in many areas from aeronautics to biomedical devices due to their high strength-to-weight ratio, excellent hardenability, good corrosion resistance and enhanced biocompatibility [1-3]. In recent years, research on metallic biomaterials has focused on the $\beta$ titanium alloys produced from nontoxic elements [4-8], particularly using Mo as the alloying element [9-11]. According to Banerjee et al. [12], the PLC effect, as a kind of plastic instability, is observed in Ti-15Mo alloy during uniaxial tension at elevated temperatures. Hence, to investigate the occurrence and development of the PLC effect in binary Ti-Mo alloys has become an imperious demand for a practical application of these materials.

The PLC effect typically manifests itself as serrated or jerky flow in stress-strain curves and localized deformation bands in specimens of metallic alloys [13]. Up to now, there is no unique mechanism for the PLC effect in different systems, though the repetitive releasing and arresting of mobile dislocations are considered as the common factor to be responsible for its occurrence [14]. For $\mathrm{Al}-\mathrm{Mg}$ alloys, the solute atoms of $\mathrm{Mg}$ are widely considered as obstacles to block and release mobile dislocations [15]. While, for Ni-based alloys, $\gamma^{\prime}$ precipitates are regarded as obstacles instead of solute atoms [16]. Focusing on titanium alloys, one of the earliest observations of the PLC effect in a commercially pure hcp titanium was reported by Garde et al. [17]. Then, Prasad et al. [18] investigated the PLC effect in $\alpha$-Ti alloys and discovered that the pinning of dislocations is related to interstitial elements like $\mathrm{C}$ and $\mathrm{N}$. Unlike $\alpha$-Ti alloys, some researchers [19-21] found that the PLC effect occurring in $\beta$-stabilized Ti-based alloys and $\mathrm{Ti}-\mathrm{Nb}$-Al intermetallics is mainly attributed to the presence of nano-scaled $\omega$ phases $(1-30 \mathrm{~nm})$ in the matrix of $\beta$ phases. Notice that $\omega$ phases can be classified as athermal $\omega\left(\omega_{\text {ath }}\right)$ or isothermal $\omega\left(\omega_{\text {iso }}\right)$, whether they are formed during the quenching 


\section{ACCEPTED MANUSCRIPT}

from high temperature or during isothermal ageing heat treatment in a specific range of temperature depending on alloy composition [22]. Furthermore, based on the investigation of Ti-15Mo (wt.\%) alloy, a mechanism proposed by Banerjee el al. [12] is used to explain the occurrence of the PLC effect in $\beta$ titanium alloys. They propose that mobile dislocations are first pinned by $\omega$ particles which form dynamically during testing at elevated temperature, then a sudden drop of the load occurs when $\omega$ precipitates are sheared. The passage of an avalanche of dislocations creates $\omega$-free soft channels wherein dynamic restoration of $\omega$ particles occurs, leading to further pinning of dislocations, resulting in the rise of the load.

Until now, some studies have been performed on the PLC effect mainly from temporal and spatial aspects. Focusing on the former, Amokhtar et al. [23] investigated the evolution of serration morphology with different Mg contents and applied strain rates. Moreover, Pozuelo et al. [24] studied the stress drop magnitude in nanostructured binary $\mathrm{Mg}-\mathrm{Al}$ alloys and discovered that it follows a linear relationship with the number of stress drops. Sarkar et al. [25] compared the stress drop magnitude in HT-9 steel at different temperatures, and the experimental results indicated that it is enlarged by increasing temperature. Furthermore, Chatterjee et al. [26] investigated the number of stress drops per unit time in $\mathrm{Al}-2.5 \mathrm{Mg}$ (wt.\%) alloy, and found that it has a strong dependence on the applied strain rate. Besides, a large amount of work [27-29] has been devoted to investigating the influences of alloying element contents and process parameters on the critical strain in Al-based alloys.

On the other hand, for the analysis of the spatial aspect, PLC bands were mainly observed by using four technologies as follows: shadowgraph [30], digital speckle pattern interferometry [31], digital image correlation [32] and infrared thermography [33]. Moreover, the propagation characteristics of PLC bands can be classified as type A, B and C, corresponding to continuous propagation, hopping 


\section{ACCEPTED MANUSCRIPT}

propagation and random nucleation, respectively [34-36]. Yuzbekova et al. [37] reported the effect of microstructure on the PLC effect in $\mathrm{Al}-3 \mathrm{Mg}(\mathrm{wt} . \%)$ alloy at a high applied strain rate, and attributed the variation of propagation types to the grain size and lattice dislocation density of the material. Furthermore, Casarotto et al. [38] investigated the type A and type B propagation of PLC bands in Al-3Mg alloy, and the results revealed that the applied strain rate of type B is lower than the one of type A. Chihab et al. [39] investigated three band propagation types in Al-5Mg (wt.\%) alloy, and discovered that the applied strain rate for the occurrence of type $\mathrm{C}$ is the lowest. Additionally, some researches [40-42] were carried out on quantitatively characterizing the width evolution of PLC bands at different testing conditions.

Note that although a large majority of studies on the PLC effect have been performed in Al-Mg alloys [43-45], steels [46-48] and Ni-based superalloys [49-51], to date, the PLC effect in metastable $\beta$ Ti-based alloys is still less reported, especially regarding the effect of temperature on serration morphologies and propagation characteristics of the PLC bands associated with different alloying element contents. In this paper, Ti-12Mo and Ti-15Mo binary alloys are synthesized and tested in tension combined with a DIC technique. Tensile tests are performed at room $\left(25^{\circ} \mathrm{C}\right)$ and elevated temperatures $\left(250^{\circ} \mathrm{C}\right.$ and $\left.350{ }^{\circ} \mathrm{C}\right)$ with an applied strain rate of the order of $10^{-3} \mathrm{~s}^{-1}$. Thereafter, the thermo-mechanical behaviors of the two above-referenced Ti-Mo alloys are investigated. In particular, the spatiotemporal aspects of the PLC effect in Ti-Mo alloys are quantitatively analyzed.

\section{Materials and experimental procedures}

Two alloys with Ti-12Mo and Ti-15Mo chemical compositions (wt.\%) are synthesized from commercially pure titanium ( $99.95 \mathrm{wt} . \%$ ) and molybdenum ( $99.99 \mathrm{wt} . \%)$ by employing cold crucible levitation melting under $\mathrm{Ar}$ atmosphere in a water-cooled $\mathrm{Cu}$ crucible [10]. Moreover, in order to 


\section{ACCEPTED MANUSCRIPT}

ensure the uniformity of compositions, the ingots are then subjected to a homogenization treatment at

$950{ }^{\circ} \mathrm{C}$ for $20 \mathrm{~h}$ followed by quenching in water. Furthermore, after removing the surface oxide layer in an acidic bath (50 vol.\% $\mathrm{HF}$ and 50 vol. $\left.\% \mathrm{HNO}_{3}\right)$, the heat treated ingots are cold rolled into plates with a $90 \%$ reduction in thickness, leading to a final thickness around $1 \mathrm{~mm}$. Thereafter, tensile test specimens with a gauge size of $15 \times 3 \times 1 \mathrm{~mm}^{3}$ are cut from the rolled plates along the rolling direction, as shown in Fig. 1(a). Finally, the specimens undergo a recrystallization treatment at $870{ }^{\circ} \mathrm{C}$ for $0.5 \mathrm{~h}$, followed by quenching in water. The microstructure is analyzed by X-ray diffraction (XRD) with a Philips PW3710 diffractometer using $\mathrm{Cu} \mathrm{K \alpha 1}$ radiation $(\lambda=0.154060 \mathrm{~nm})$ and optical micrographs $(\mathrm{OM})$. Prior to $\mathrm{OM}$ observations, samples are first mechanically polished with $\mathrm{SiC}$ abrasive papers, then mirror polished with a colloidal silica suspension (particle size: $50 \mathrm{~nm}$ ) and finally chemically etched with a $5 \% \mathrm{HNO}_{3}, 5 \% \mathrm{HF}$ and $90 \% \mathrm{H}_{2} \mathrm{O}$ solution (vol.\%). The diffractograms and optical micrographs are presented in Figs. 1(b) and (c), respectively. It can be found that the microstructures of the above specimens are basically the same after the whole elaboration process; they are both only constituted of $\beta$ phase and the fully recrystallized microstructure is composed of equiaxial grains with a size of about $60-80 \mu \mathrm{m}$. 


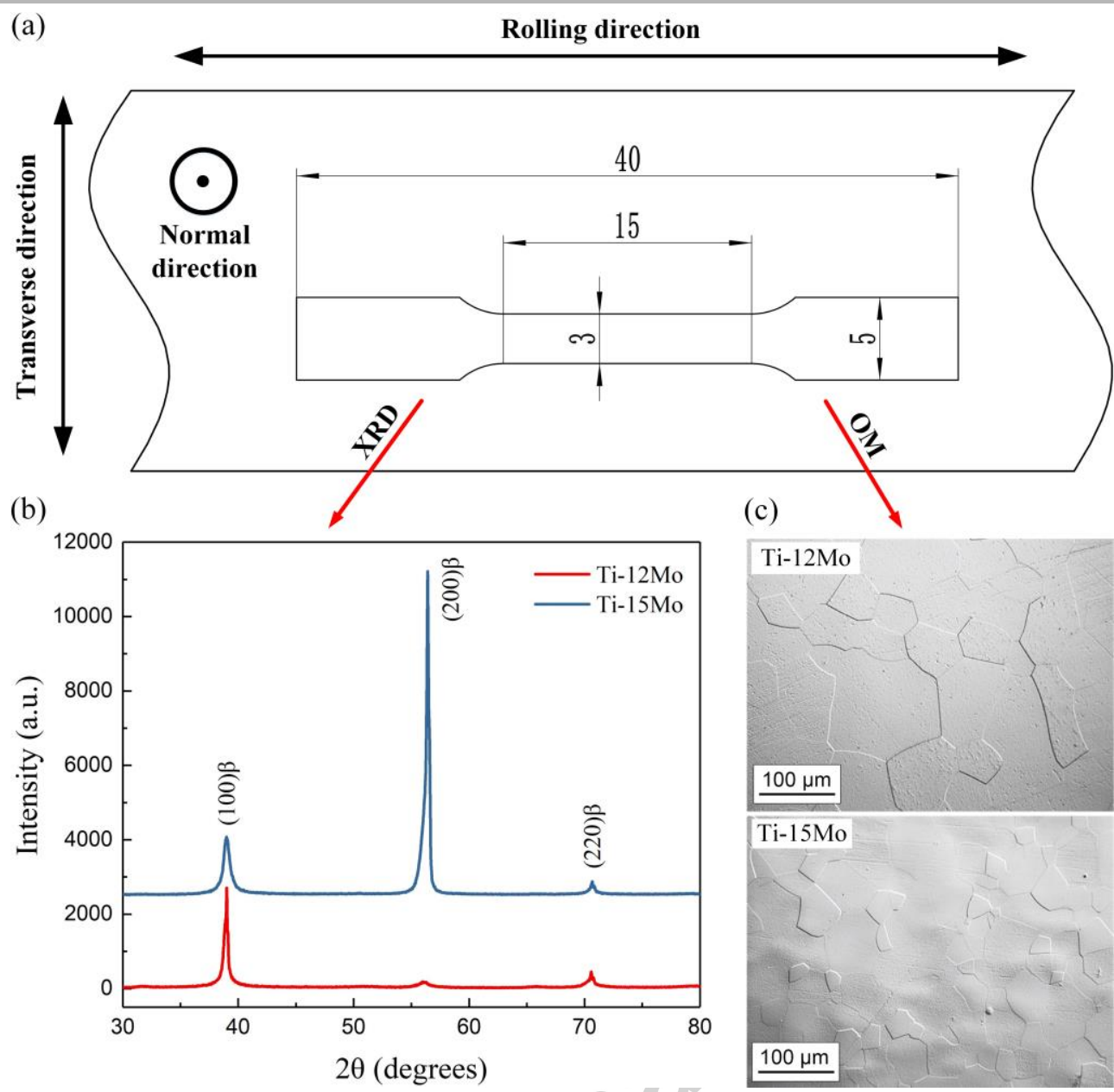

Fig. 1. Dimensions of tensile specimen in mm (a), XRD diffractograms (b) and OM observations (c) of both Ti-12Mo and Ti-15Mo alloys.

Subsequently, tensile tests are conducted at room temperature as well as $250{ }^{\circ} \mathrm{C}$ and $350{ }^{\circ} \mathrm{C}$ with an applied strain rate of the order of $10^{-3} \mathrm{~s}^{-1}$, using INSTRON 5566A universal tensile testing equipment and Gleeble 3500 testing machine, as shown in Figs. 2(a) and (b), respectively. Moreover, a black and white contrast pattern is sprayed over the specimen surface prior to tests, as shown in the partial enlarged drawings of Fig. 2. During the tests, the deformation characteristics of specimen surfaces are captured continuously at a rate of 4 frames per second until rupture with DIC (Aramis). For tensile tests at elevated temperatures, samples are heated to $250{ }^{\circ} \mathrm{C}$ or $350{ }^{\circ} \mathrm{C}$ using a constant heating rate of $10{ }^{\circ} \mathrm{C} . \mathrm{s}^{-1}$, followed by a holding time of $10 \mathrm{~s}$ prior to the test. The fluctuations of temperature measured by thermocouples are maintained within $2{ }^{\circ} \mathrm{C}$ during the whole tensile process. 


\section{ACCEPTED MANUSCRIPT}

Furthermore, in order to eliminate the influence of temperature gradients, only a small area with a length of $5 \mathrm{~mm}$ at the specimen center is selected to observe the PLC effect in Ti-Mo alloys where temperature heterogeneity remains rather small (7\%), as shown in Fig. 2(c). The load-time curves obtained from tensile testing machines and strain-time curves measured by Aramis software are coupled and converted to engineering stress-strain curves using a linear interpolation; the average engineering strain is calculated by using a gauge length of $10 \mathrm{~mm}$. Notice that each experimental test is repeated three times to ensure the reproducibility of the results.
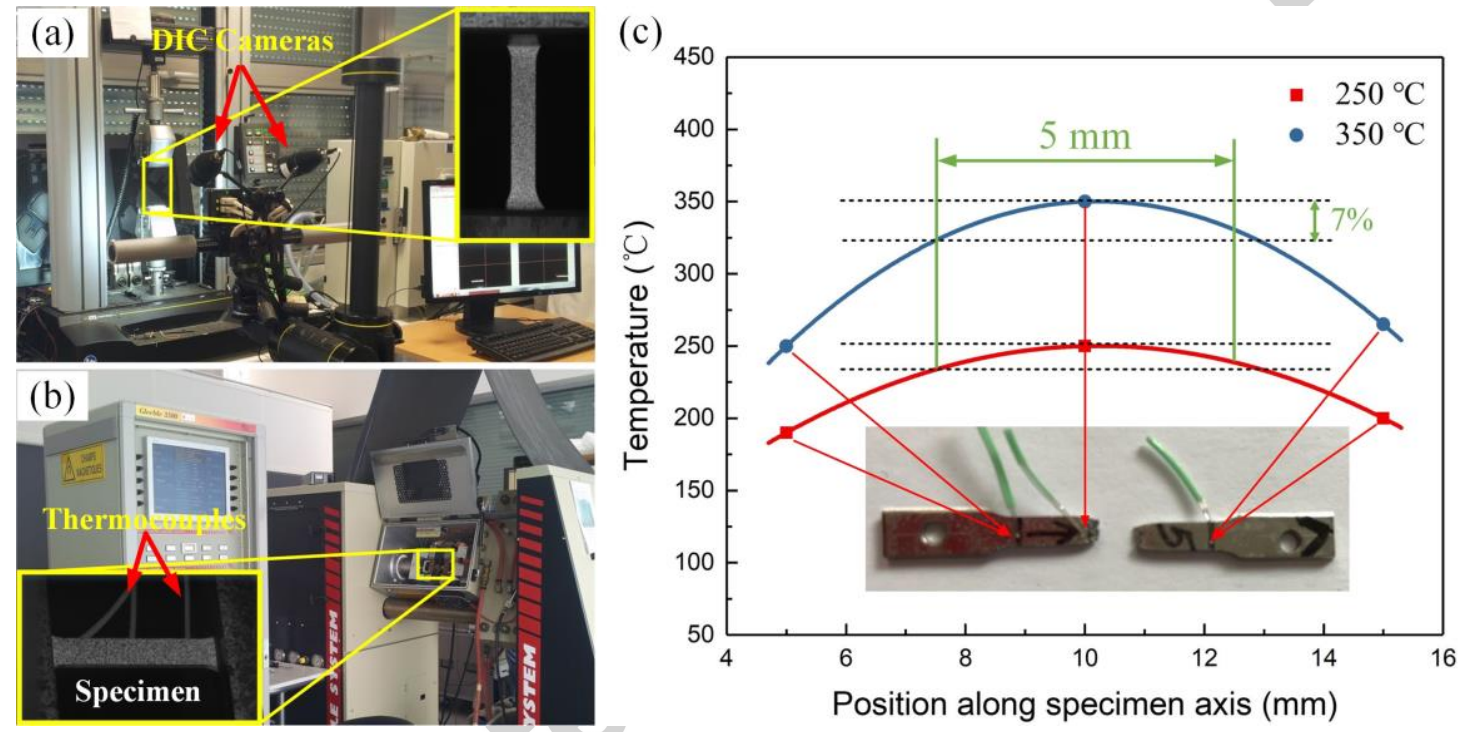

Fig. 2. Experimental setups of Ti-Mo alloy tensile tests at room (a) and elevated temperatures (b) as

well as temperature distribution along specimen axis (c).

\section{Results and discussion}

\subsection{Stress-strain curves and mechanical properties}

Fig. 3 shows the engineering stress-strain curves obtained with different Mo contents in the temperature range of $25-350{ }^{\circ} \mathrm{C}$. It can be seen that no jerky flow is recorded at room temperature whereas serrated flow is observed at high temperature, which is similar to the phenomenon reported by Sarkar et al. [25]. Moreover, the serration morphology, related to the intensity of the interaction 


\section{ACCEPTED MANUSCRIPT}

between mobile dislocations and obstacles, obviously changes at different temperatures. Based on the classification method of the PLC bands described by Manach et al. [34], it can be found from Fig. 3(a) that the serration type of Ti-12Mo alloy transforms from type $(\mathrm{A}+\mathrm{B})$ to type $\mathrm{B}$ and simultaneously the stress drop magnitude increases as the temperature increases. This is mainly because a relatively higher temperature contributes to a faster precipitation of $\omega$ particles, thereby resulting in enhancing the interaction between $\omega$ phases and mobile dislocations, further increasing the stress drop magnitude. This explanation is quite different from the traditionally accepted solute-dislocation interactions, and has been proposed by Banerjee et al. [12]. Furthermore, compared with the mixed serration type of Ti-12Mo alloy at $250^{\circ} \mathrm{C}$, it can be found from Fig. 3(b) that the serration type of Ti-15Mo alloy is pure type A, and the stress drop magnitude is relatively lower. In addition, no jerky flow was previously recorded for Ti-25Mo alloy [12]. These phenomena can be attributed to the fact that Mo alloying element renders the $\beta$ phase matrix more stable against the $\beta$ to $\omega$ transformation, resulting in a lower fraction of $\omega$ phase particles, further leading to a weaker intensity of precipitate-dislocation interactions. This view can be indirectly supported by the recent investigation of Wang et al. [3] which found the formation of $\omega$ phase is suppressed with increasing Mo content in water-quenched Ti-Mo alloy specimens by using bright-field transmission electron microscopy observations. 
(a)

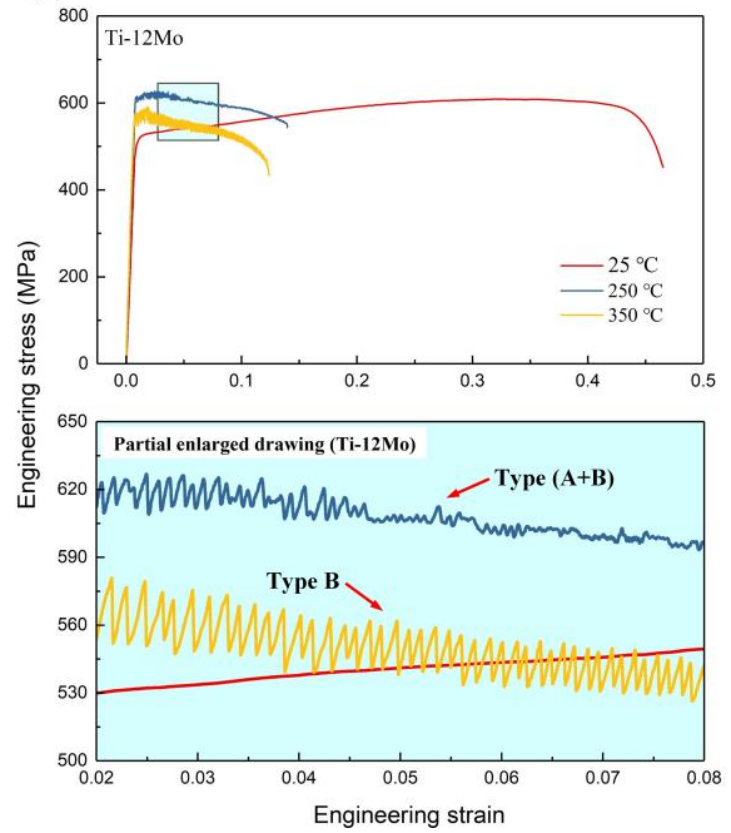

(b)
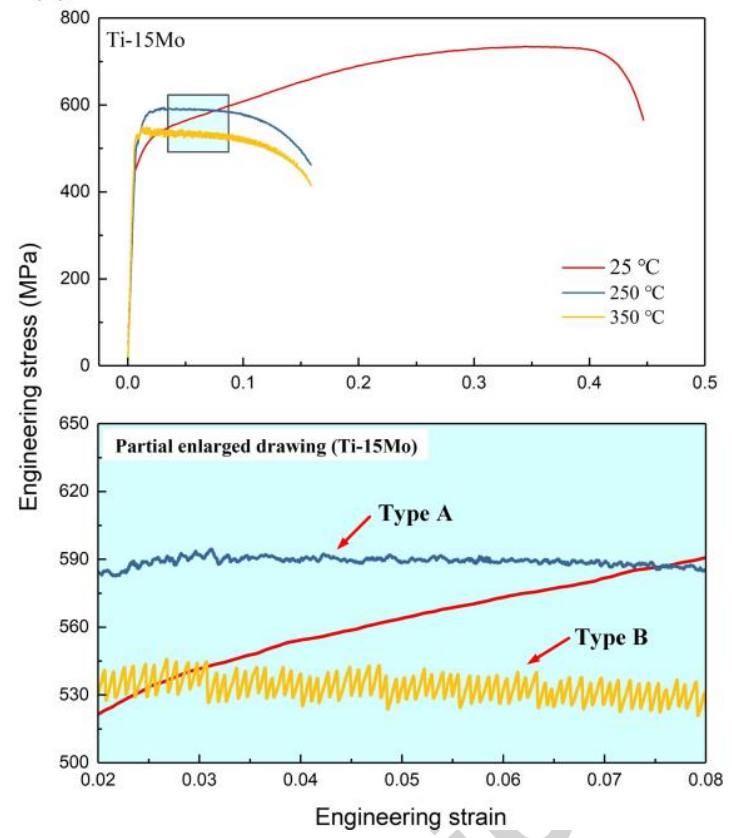

Fig. 3. Engineering stress- strain curves in the temperature range of $25-350{ }^{\circ} \mathrm{C}$ for $\mathrm{Ti}-12 \mathrm{Mo}$ (a) and

$$
\text { Ti-15 Mo (b) alloys. }
$$

Fig. 4 shows the mechanical property evolution of Ti-12Mo and Ti-15Mo alloys in the temperature range of $25-350{ }^{\circ} \mathrm{C}$, corresponding to the engineering stress-strain curves presented in Fig. 3. It can be seen from Fig. 4(a) that, for Ti-12Mo alloy, the value of $0.2 \%$ offset yield strength (YS) decreases at the level of $615 \mathrm{MPa}$ after a sharp increase when the temperature increases to a medium value of $250{ }^{\circ} \mathrm{C}$ from $25^{\circ} \mathrm{C}$, which is highly consistent with the results reported by Banerjee et al. [12]. This phenomenon can be explained by a combination of the strengthening effect of $\omega$ phase particles and temperature softening effect. Increasing temperature results in the precipitation of $\omega$ phase, leading to an additional stress required by mobile dislocations to overcome $\omega$ phase particles. After $250{ }^{\circ} \mathrm{C}$, however, the strengthening effect of $\omega$ phase particles is insufficient to compensate the temperature softening effect, which causes the decrease of YS. Like Ti-12Mo alloy, the YS evolution of Ti-15Mo alloy shows the same tendency though its value is relatively smaller. This is mainly because a higher Mo content weakens the formation ability of $\omega$ phase, thereby resulting in a lower strengthening effect 


\section{ACCEPTED MANUSCRIPT}

caused by such particles. Moreover, it can be seen from Fig. 4(b) that, for Ti-12Mo alloy, the value of Young's modulus (measured in the strain range of $0.05 \sim 0.4 \%$ ) at $25{ }^{\circ} \mathrm{C}$ is close to $90 \mathrm{GPa}$, which is consistent with the result reported by Sun et al. [10]. Furthermore, there is a nearly $7 \%$ increase in the Young's modulus value of both Ti-12Mo and Ti-15Mo alloys by increasing the temperature from $25^{\circ} \mathrm{C}$ to $350{ }^{\circ} \mathrm{C}$. This phenomenon can be explained by the fact that the Young's modulus of $\omega$ phase is higher than the one of $\beta$ phase [52] and by the influence of Mo content on the $\beta$ to $\omega$ transformation as mentioned above. Unlike the Young's modulus, the temperature has an opposite influence on the elongation at fracture (EI) which is calculated by using the gauge length of $10 \mathrm{~mm}$. There is a nearly $80 \%$ decrease in the EI value of both Ti-Mo alloys by increasing the temperature from $25^{\circ} \mathrm{C}$ to $350{ }^{\circ} \mathrm{C}$. This is mainly because increasing temperature contributes to the precipitation of $\omega$ phase which causes the continuous localized flow within the PLC bands, leading to an extremely low elongation at fracture. Besides, it can be seen that the EI is the mechanical property the most sensitive to the PLC effect. In addition, the Ti-12Mo alloy is known to exhibit a high elongation at fracture at room temperature due to the combination of Transformation Induced Plasticity (TRIP) and Twinning Plasticity (TWIP) effects [53]. As both effects are temperature dependent, it can be assumed that both twinning and stress-induced phase transformation mechanisms are suppressed at high temperature, that also explains the strong decrease of ductility when increasing the temperature. 
(a)

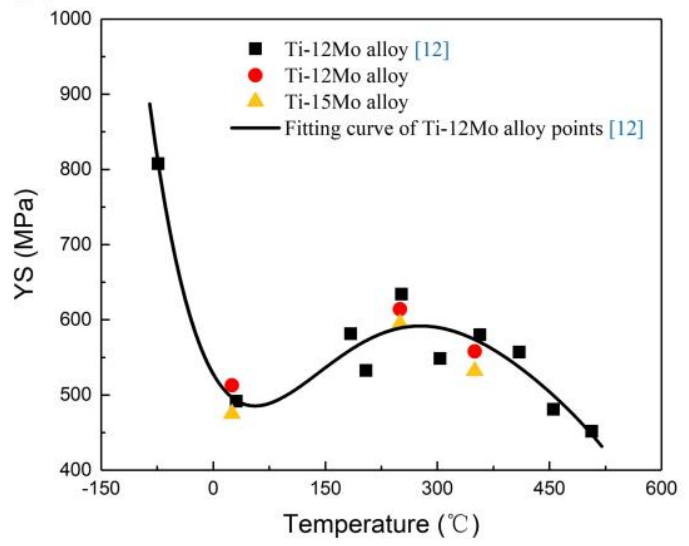

(b)

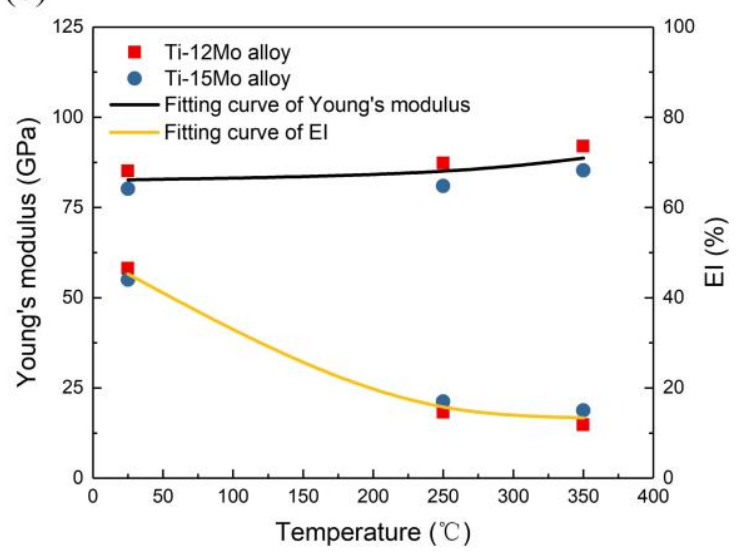

Fig. 4. Mechanical property evolution of Ti-12Mo and Ti-15Mo alloys in the temperature range of $25-350{ }^{\circ} \mathrm{C}$.

\subsection{Stress drop magnitude and the number of stress drops per unit time}

To better reveal the intensity and frequency evolution characteristics of the PLC effect in Ti-Mo alloys presented in Fig. 3, the stress drop magnitude and the number of stress drops per unit time at $350{ }^{\circ} \mathrm{C}$ with different Mo contents are selected and analyzed quantitatively, as shown in Fig. 5. Similar tendencies are observed at $250^{\circ} \mathrm{C}$ though the results are not presented here. It can be seen from Fig. 5(a) that the stress drop magnitude of both $\mathrm{Ti}-12 \mathrm{Mo}$ and Ti-15Mo alloys shows a generally decreasing trend with the increase of engineering strain until rupture, corresponding to the reduced intensity of the PLC effect. These results appear to be opposite to those reported by Amokhtar et al. [23], who found that the stress drop magnitude is nearly proportional to strain in Al-Mg alloys. Combined with the dynamic strain aging (DSA) theory which considers stress drop magnitude as a function of solute concentration, the above finding indicates that the concentration of $\omega$ phase clustered around dislocations is reduced with increasing strain. This is mainly because the reconstruction rate of $\omega$ particles is lower than the destruction rate during the occurrence of the PLC effect. This explanation can be indirectly supported by Choudhuri et al. [20], who found that $\omega$ phase particles are sheared by mobile dislocations during the deformation process, leading to a significant decrease of $\omega$ phase concentration within the PLC 


\section{ACCEPTED MANUSCRIPT}

bands in a $\beta$-stabilized Ti-Mo-Nb-Al alloy. Moreover, it is observed that the stress drop magnitude of both Ti-Mo alloys decreases over $50 \%$ and is approximately the same (about $7.5 \mathrm{MPa}$ ) when the deformation process enters the final stage, although there is a dramatically difference at the beginning stage. This phenomenon can also be related to the concentration of $\omega$ phase particles influenced by Mo contents as well as the destruction and reconstruction rates of $\omega$ phase. In addition, unlike the stress drop magnitude, the number of stress drops per unit time shows an opposite evolution trend with increasing the engineering strain, as shown in Fig. 5(b). This can be attributed to the fact that a larger stress drop magnitude is accompanied by a longer pinning time, resulting in a lower frequency of stress drops.

(a)

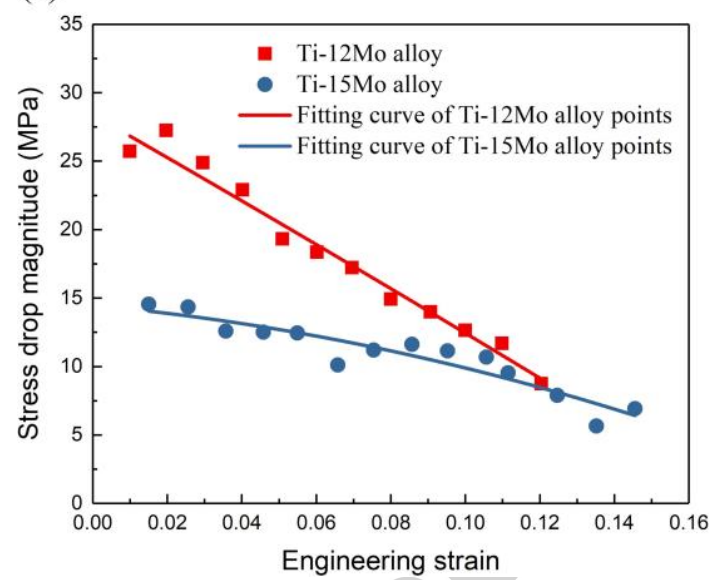

(b)

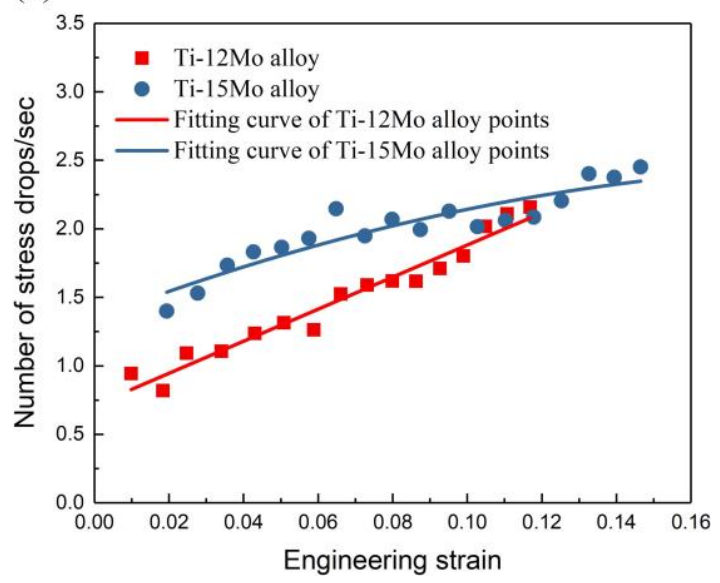

Fig. 5. Evolutions of stress drop magnitude (a) and the number of stress drops per second (b) at $350{ }^{\circ} \mathrm{C}$ with different Mo contents.

\subsection{Propagation characteristics of the PLC bands}

Fig. 6 shows the propagation characteristics of the PLC bands described by strain rate maps, corresponding to the engineering stress-strain curves presented in Fig. 3. In order to provide a maximum contrast, the color scale is independent for each frame, based on the instantaneous maximum and minimum values of strain rates. The corresponding maximum strain rate and time are indicated 


\section{ACCEPTED MANUSCRIPT}

over and under each frame, respectively. It can be observed that the distribution of strain rate at room temperature is relatively uniform and no localized bands appear in Fig. 6(a), while continuous propagation bands (type A) are exhibited in Ti-15Mo alloy at a higher temperature $\left(250{ }^{\circ} \mathrm{C}\right)$, as shown in Fig. 6(b). This phenomenon is highly consistent with the stress-strain curves and can be explained by the temperature effect mentioned in section 3.1. Moreover, compared with the former one, Fig. 6(c) shows the mixed propagation (type $(A+B))$ characteristics, which consists of continuous and hopping propagations. The main reason for the transformation of propagation types is that a relatively lower content of Mo alloying element contributes to strengthening the interactions between $\omega$ phase particles and mobile dislocations, resulting in a larger stress drop magnitude (Fig. 5(a)), and further leading to a higher reloading time. Therefore, it will provide more time for the plastic relaxation of the internal stress, thereby resulting in a smaller spatial coupling force, that comes from elastic stresses related to local plastic incompatibilities and controls the band propagation [54], further causing the switch from type A to type $(A+B)$. This view is supported by Cai et al. [13], who reported that the variation of spatial coupling strength is responsible for the change of band propagation types. Furthermore, Fig. 6(d) shows a typical type B propagation characterized by discontinuous hopping, and its maximum strain rate value is almost double that of type $(A+B)$ presented in Fig. 6(c), which suggests that the strain localization is increased within the deformation band. These results are in agreement with those reported earlier by Amokhtar et al. [23], who also found that the strain rate increases with increasing the stress drop magnitude in Al-Mg alloys. 


\section{ACCEPTED MANUSCRIPT}

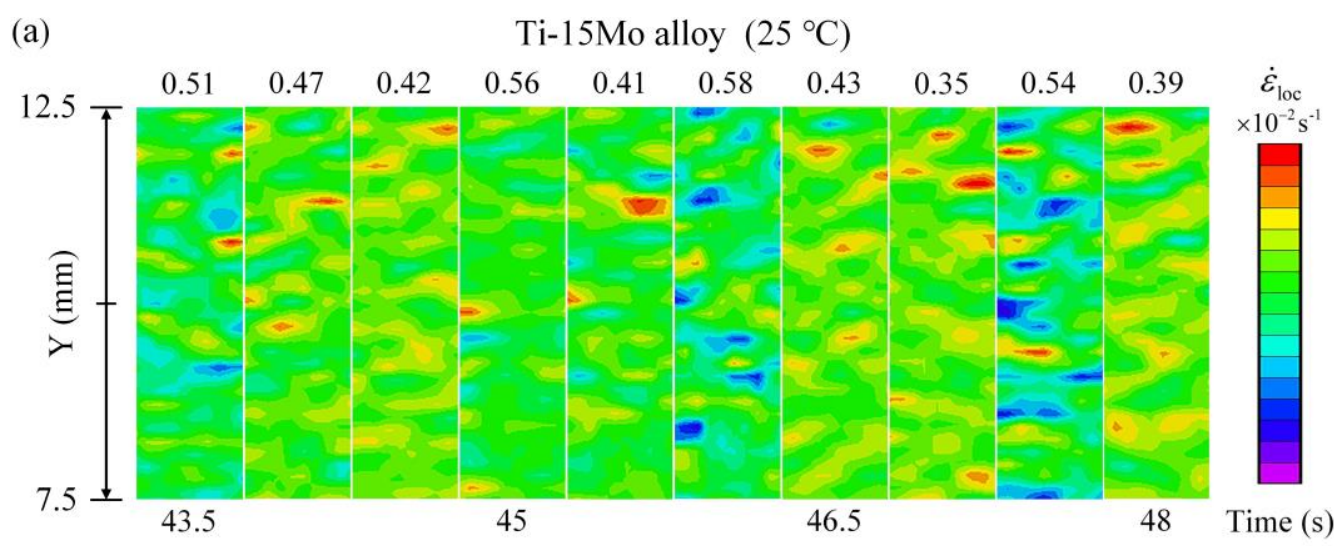

(b)

Ti-15Mo alloy $\left(250^{\circ} \mathrm{C}\right)$

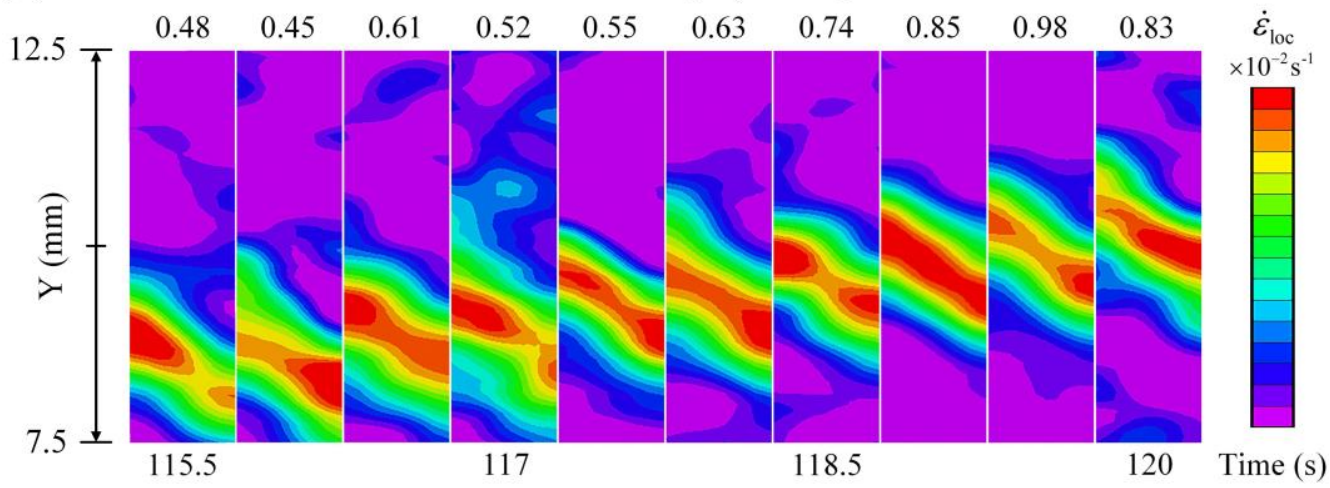

(c)

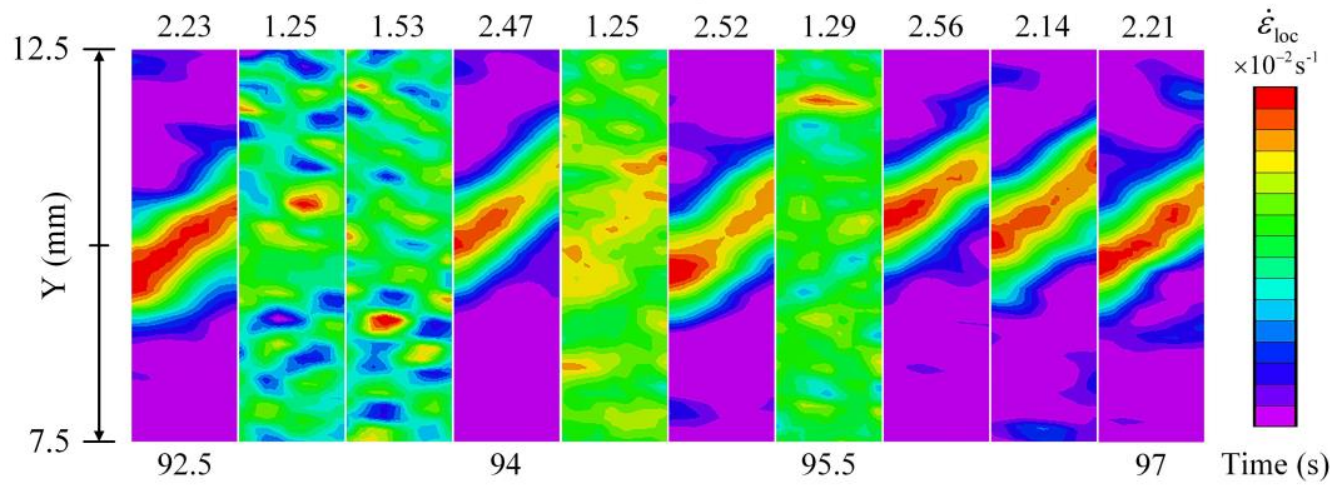

(d) Ti-12Mo alloy $\left(350^{\circ} \mathrm{C}\right)$

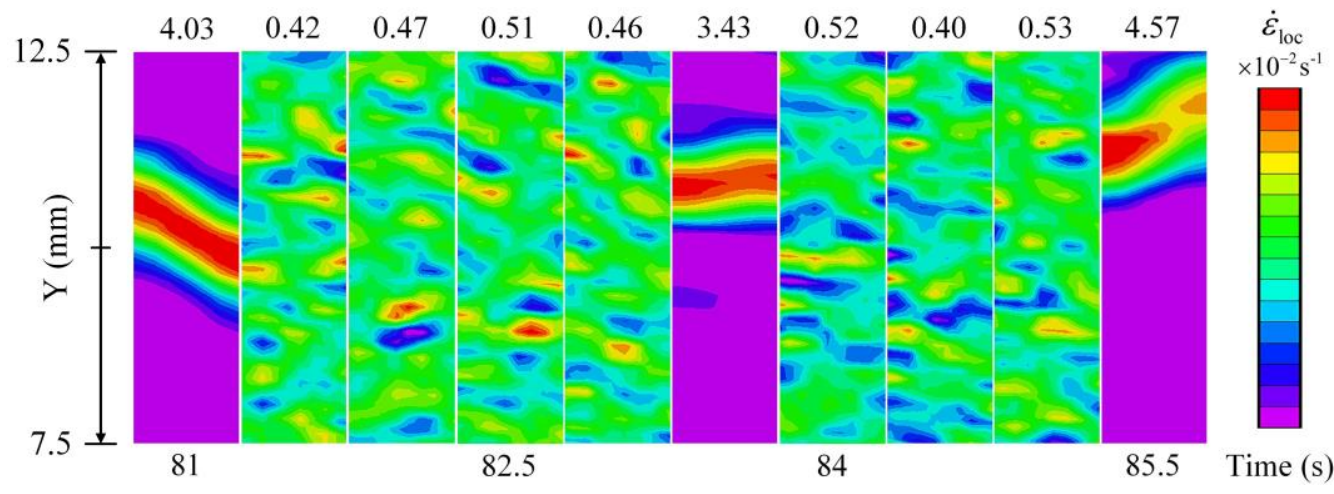

Fig. 6. Propagation characteristics of the PLC bands described by strain rate maps. Y-axis is

parallel to the tensile direction. 


\section{Conclusions}

In the present paper, using uniaxial tensile test coupled with DIC technology, the thermo-mechanical behaviors of Ti-12Mo and Ti-15Mo alloys in a temperature range of $25-350{ }^{\circ} \mathrm{C}$ with an applied strain rate of the order of $10^{-3} \mathrm{~s}^{-1}$ are investigated. In particular, the influence of temperature on several characteristics of the PLC effect in Ti-Mo alloys associated with different Mo contents is detailed. The following conclusions are achieved:

(1) The value of $0.2 \%$ offset yield strength decreases after a sharp increase as increasing temperature, depending on a combination of the strengthening effect of $\omega$ phase particles and temperature softening effect. Moreover, Young's modulus value increases as increasing temperature, which is mainly attributed to the precipitation of $\omega$ phase. In contrast, the elongation at fracture value decreases with the increase of temperature due to the occurrence of localized flow within the PLC bands. Besides, the elongation at fracture is the mechanical property the most significantly influenced by the PLC effect in Ti-Mo alloys.

(2) The stress drop magnitude is found to be positively correlated to temperature and negatively correlated to strain and Mo contents, while the number of stress drops per unit time shows an opposite trend. These findings indicate that the PLC effect of Ti-Mo alloys can be suppressed by decreasing temperature as well as increasing strain and Mo content which can be attributed to the reduced precipitation of $\omega$ phase, further leading to a weaker intensity of interactions between $\omega$ phase particles and mobile dislocations.

(3) The propagation types of the PLC bands are observed to be highly dependent on temperature and Mo content in Ti-Mo alloys. A relatively higher temperature and lower Mo content lead to the transformation of the propagation from type A to type B and the increase of the strain rate within 


\section{ACCEPTED MANUSCRIPT}

the bands. These findings imply that the spatial cohesion of the bands is weakened and strain localization is strengthened within the PLC bands with the increase of temperature and decrease of Mo content, which are related to the increased precipitation of $\omega$ phase.

\section{Acknowledgements}

The authors would like to gratefully acknowledge the financial support from the People Programme (Marie Curie Actions) of the European Union's Seventh Framework Programme (FP7/2007-2013) under REA grant agreement n. PCOFUND-GA-2013-609102, through the PRESTIGE programme coordinated by Campus France.

\section{References}

[1] S. Joseph, I. Bantounas, T.C. Lindley, D. Dye, Int. J. Plast. 100 (2018) 90-103.

[2] S.Y. Luo, D.H. Zhu, L. Hua, D.S. Qian, S.J. Yan, Int. J. Mech. Sci. 123 (2017) 260-270.

[3] C.H. Wang, M. Liu, P.F. Hu, J.C. Peng, J.A. Wang, Z.M. Ren, G.H. Cao, J. Alloy. Compd. 720 (2017) 488-496.

[4] M. Tahara, H.Y. Kim, H. Hosoda, S. Miyazaki, Acta Mater. 57 (2009) 2461-2469.

[5] E. Bertrand, T. Gloriant, D.M. Gordin, E. Vasilescu, P. Drob, C. Vasilescu, S.I. Drob, J. Mech. Behav. Biomed. Mater. 3 (2010) 55.

[6] M. Abdel-Hady Gepreel, M. Niinomi, J. Mech. Behav. Biomed. Mater. 20 (2013) 407-415.

[7] A. Ramarolahy, P. Castany, F. Prima, P. Laheurte, I. Péron, T. Gloriant, J. Mech. Behav. Biomed. Mater. 9 (2012) 83-90.

[8] P. Castany, D.M. Gordin, S.I. Drob, C. Vasilescu, V. Mitran, A. Cimpean, T. Gloriant, Shape Memory and Superelasticity 2 (2016) 18-28.

[9] F.F. Cardoso, P.L. Ferrandini, E.S.N. Lopes, A. Cremasco, R. Caram, J. Mech. Behav. Biomed. 


\section{ACCEPTED MANUSCRIPT}

Mater. 32 (2014) 31-38.

[10] F. Sun, F. Prima, T. Gloriant, Mater. Sci. Eng. A 527 (2010) 4262-4269.

[11] K. Endoh, M. Tahara, T. Inamura, H. Hosoda, J. Alloys Compd. 695 (2017) 76-82.

[12] S. Banerjee, U.M. Naik, Acta Metall. 44 (1996) 3667-3677.

[13] Y.L. Cai, S.L. Yang, S.H. Fu, D. Zhuang, Q.C. Zhang, J. Mater. Sci. Technol. 33 (2017) 580-586.

[14] A. Portevin, F.L. Chatelier, C.R. Acad. Sci. 176 (1923) 507.

[15] T. Tabata, H. Fujtta, Y. Nakajima, Acta Metall. 28 (1980) 795-805.

[16] Y.L. Cai, C.G. Tian, S.H. Fu, G.M. Han, C.Y. Cui, Mater. Sci. Eng. A 638 (2015) 314-321.

[17] A.M.Garde, A.T. Santhanam, R.E.R. Hill, Acta Metall. 20 (1972) 215-220.

[18] K. Prasad, A. Amrithapandian, B.K. Panigrahi, V. Kumar, K.B. Sankara-Rao, M. Sundararaman, Mater. Sci. Eng. A 638 (2015) 90-96.

[19] S. Banerjee, P. Mukhopadhyay, Phase Transformations: Examples From Titanium and Zirconium Alloys, Elsevier Science, Oxford, 2010.

[20] D. Choudhuri, S.A. Mantri, T. Alam, S. Banerjee, R. Banerjee, Scr. Mater. 124 (2016) 15-20.

[21] R.J. Grylls, S. Banerjee, S. Perungulam, R. Wheeler, H.L. Fraser, Intermetallics 6 (1998) 749752.

[22] Y.F. Xu, D.Q. Yi, H.Q. Liu, B. Wang, F.L, Yang, Mater. Sci. Eng. A 529 (2011) 326-334.

[23] H.A. Amokhtar, S. Boudrahem, C. Fressengeas, Scr. Mater. 54 (2006) 2113-2118.

[24] M. Pozuelo, Y.W. Chang, J. Marian, J.M. Yang, Scr. Mater. 127 (2017) 178-181.

[25] A. Sarkar, S. A. Maloy, K.L. Murty, Mater. Sci. Eng. A 631 (2015) 120-125.

[26] A. Chatterjee, A. Sarkar, P. Barat, P. Mukherjee, N. Gayathri, Mater. Sci. Eng. A 508 (2009) $156-160$ 


\section{ACCEPTED MANUSCRIPT}

[27] H.A. Amokhtar, C. Fressengeas, K. Bouabdallah, Mater. Sci. Eng. A 631 (2015) 209-2013.

[28] N. Chibane, H.A. Amokhtar, C. Fressengeas, Scr. Mater. 130 (2017) 252-255.

[29] K.S.V.B.R. Krishna, K.C. Sekhar, R. Tejas, N.N. Krishna, K. Sivaprasad, R. Narayanasamy, K. Venkateswarlu, Mater. Des. 67 (2015) 107-117.

[30] S.H. Fu, G. Yue, Y.L. Cai, T. Cheng, Q.C. Zhang, X.P. Wu, Measurement. 72 (2015) 61-67.

[31] Q.C. Zhang, Z.Y. Jiang, H.F. Jiang, Z.J. Chen, X.P. Wu, Int. J. Plast. 21 (2005) 2150-2173.

[32] B.H. Sun, N. Vanderesse, F. Fazeli, C. Scott, J.Q. Chen, P. Bocher, M. Jahazi, S. Yue, Scr. Mater. 133 (2017) 9-13.

[33] D. Delpueyo, X. Balandraud, M. Grédiac, Mater. Sci. Eng. A 651 (2016) 135-145.

[34] P.Y. Manach, S. Thuillier, J.W. Yoon, J. Coër, H. Laurent, Int. J. Plast. 58 (2014) 66-83.

[35] Y.L. Cai, S.L. Yang, Y.H. Wang, S.H. Fu, Q.C. Zhang, Mater. Sci. Eng. A 664 (2016) 155-164.

[36] M.N. Gussev, N. Sridharan, M. Norfolk, K.A. Terrani, S.S. Babu, Mater. Sci. Eng. A 684 (2017) $606-616$

[37] D. Yuzbekova, A. Mogucheva, D. Zhemchuzhnikova, T. Lebedkina, M. Ledyodkin, R. Kaibyshev, Int. J. Plast. 96 (2017) 210-226.

[38] L. Casarotto, H. Dierke, R. Tutsch, H. Neuhäuser, Mater. Sci. Eng. A 527 (2009) 132-140.

[39] K. Chihab, Y. Estrin, L.P. Kubin, J. Vergnol. Scr. Metall. 21 (1987) 203-208.

[40] M. Callahan, O. Hubert, F. Hild, A. Perlade, J.H. Schmitt, Mater. Sci. Eng. A 704 (2017) 391-400.

[41] X.G. Wang, L. Wang, M.X. Huang, Acta Mater. 124 (2017) 17-19.

[42] N. Ranc, W. Du, I. Ranc, D. Wagner, Mater. Sci. Eng. A 633 (2016) 166-173.

[43] D.A. Zhemchuzhnikova, M.A. Lebyodkin, T.A. Lebedkina, R.O. Kaibyshev, Mater. Sci. Eng. A $639(2015) 37-41$ 


\section{ACCEPTED MANUSCRIPT}

[44] W.H. Wang, D. Wu, S.S.A. Shah, R.S. Chen, C.S. Lou, Mater. Sci. Eng. A 649 (2016) 214-221.

[45] S.Z. Niu, H.C. Kou, Y. Zhang, J. Wang, J.S. Li, Mater. Sci. Eng. A 702 (2017) 96-103.

[46] X.D. Bian, F.P. Yuan, X.L. Wu, Mater. Sci. Eng. A 696 (2017) 220-227.

[47] Z.H. Cai, H. Ding, R.D.K. Misra, S.Q. Qiguan, Mater. Sci. Eng. A 652 (2016) 205-211.

[48] J.Y. Min, L.G.H. Jr, L. Zhang, L. Sun, J.E. Carsley, J.P. Lin, Mater. Des. 95 (2016) 370-385.

[49] Y.L. Cai, C.G. Tian, G.L. Zhang, G.M. Han, S.L. Yang, S.H. Fu, C.Y. Cui, Q.C. Zhang, J. Alloy. Compd. 690 (2017) 707-715.

[50] W.J. Kuang, G.S. Was, Scr. Mater. 107 (2015) 107-110.

[51] L. Yuan, X.Y. Gao, X.Q. Zhang, Y.A. Yang, Mater. Sci. Eng. A 680 (2017) 115-120.

[52] M. Tane, Y. Okuda, Y. Todaka, H. Ogi, A. Nagakubo, Acta Mater. 61 (2013) 7543-7554.

[53] M. Marteleur, F. Sun, T. Gloriant, P. Vermaut, P.J. Jacques, F. Prima, Scripta Mater. 66 (2012) $749-752$

[54] C. Fressengeas, A.J. Beaudoin, M. Lebyodkin, L.P. Kubin, Y. Estrin, Mater. Sci. Eng. A 40-41 (2005) 226-230. 